\title{
Application of highwall mining system in weak geological condition
}

\author{
Takashi Sasaoka $^{1} \cdot$ Tri Karian $^{1} \cdot$ Akihiro Hamanaka $^{1} \cdot$ Hideki Shimada $^{1} \cdot$ Kikuo Matsui $^{1}$
}

Received: 23 June 2015/Revised: 13 October 2015/Accepted: 22 January 2016/Published online: 29 April 2016

(C) The Author(s) 2016. This article is published with open access at Springerlink.com

\begin{abstract}
Almost all the coal is produced from open cut mines in Indonesia. As a consequence of open cut mine application, a great deal of coal is left out in the highwalls of the mined-out pits. Highwall mining systems can be used to recover this coal. The use of highwall mining systems has increasingly come into play in the US and Australia. However, it is not common in Indonesia. Moreover, Indonesia coal measure is categorized as weak geological condition. Some problems are likely to arise during the application of the highwall mining system for example instability of openings and highwalls due to the roof and pillar failures. Therefore, study of highwall mining system application in Indonesia is needed in order to increase the recovery rate of coal mining in Indonesia. This paper described the characteristics of the highwall mining system and discussed the appropriate highwall mining system application in weak geological condition, Indonesia. From the results of a series of laboratory tests and numerical analyses, it can be concluded that the stability of pillars and mine openings in auger mining systems is much higher than that in CHM and an auger mining system is suitable for such as very weak/poor strata conditions. Moreover, the application of backfilling system is very effective for improvement of the stability of pillar and openings.
\end{abstract}

Keywords Open cut mine $\cdot$ Left out coal $\cdot$ Highwall mining systems $\cdot$ Weak geological condition

\section{Introduction}

Indonesia produces over $400 \mathrm{Mt}$ of clean coal and is the second largest coal exporter to Japan, accounting for about $32 \mathrm{Mt}$ of coal annually. Over $99 \%$ of the coal produced in Indonesia comes from surface mines. More open cut mines will be developed and more coal will be mined in order to fill the great demand both in Indonesia and the rest of the world.

In open cut mines in Indonesia, there are many sites where mining operations have developed long highwalls which have been abandoned due to the current economic condition. Mining operations is then transferred to lower

Takashi Sasaoka

sasaoka@mine.kyushu-u.ac.jp

1 Department of Earth Resources Engineering, Kyushu University, Fukuoka 819-0395, Japan stripping ratio blocks of coal or overlying seams. It is estimated that a great deal of coal beneath abandoned in the highwall. Considering these situations, it seems to be worth introducing highwall mining systems into Indonesian open cut mines.

Final highwalls of open cut mines can form the starting point for other mining methods, such as highwall or underground mining. In its basic application, highwall mining is a technique utilized after an open cut portion of a reserve has been mined, sometimes prior to the introduction of underground mining (Seib 1993). In this system, the coal seam is mined by remotely operated equipment, such as an auger machine or a modified continuous miner incorporated into a highwall mining system (Fig. 1). Major issues of highwall mining systems are less coal recovery due to leaving coal as the pillars and the instability of openings and highwalls due to the pillar and roof failures. These geotechnical and operational issues have been occurring in Indonesia when the conventional highwall 


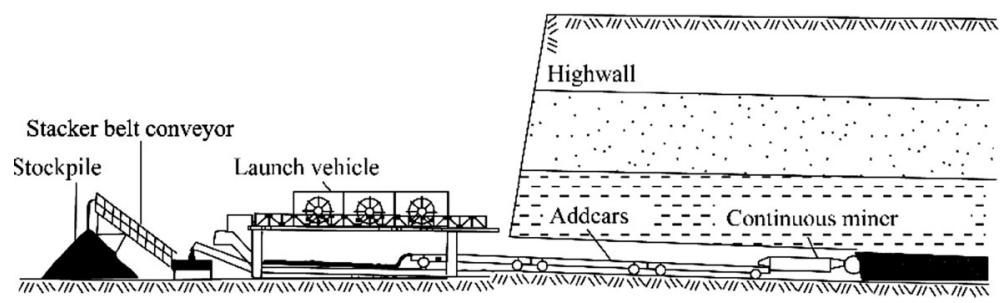

Fig. 1 Schematic of highwall mining system (Seib 1993)

mining system was introduced because of its weak geological conditions.

This paper describes the characteristics of the highwall mining system and discusses the appropriate highwall mining system in Indonesia including the application of the backfilling system to improve the stability of excavated highwall.

\section{Highwall mining systems}

Many coal seams that are presently uneconomical or technically unsuitable for conventional surface mining techniques can be recovered using highwall mining systems. Final highwalls of open cut coal mines can form the starting point for other mining methods, such as highwall or underground mining. In its basic application, highwall mining is a technique utilized after the open cut portion of a reserve has been mined, sometimes prior to the introduction of underground mining (Seib 1993).

In these mining systems, a continuous miner or an auger machine is primarily used to extract coal from the highwalls. Recently other systems such as Bucyrus Highwall Miners (formerly Superior Highwall Miners) and American Highwall Systems have been introduced in the US (The Virginia Center for Coal and Energy Research 2008).

The continuous miner system is called a continuous highwall mining (CHM) system and is categorized into two types: one is an Addcar system and the other is an Archveyor system. The former consists of a continuous miner, addcars (belt conveyor cars), a launch vehicle, a stacker conveyor and a loader as shown in Fig. 2. The latter consists of a continuous miner, archveyor chain conveyor that conveys coal and trams the machine system itself, and a loadout vehicle as shown in Fig. 3.

The CHM system can excavate rectangular holes over $350 \mathrm{~m}$ long and the size of the hole depends on the specifications of the continuous miner. Fully automated control of the system is achieved with the aid of advanced navigation technology, including a roof and floor passive gamma detector system, inclinometers, a ring laser gyroscope and programmable logic controller (PLC).
The auger system, as shown in Fig. 4, is very simple and can excavate holes over $100 \mathrm{~m}$ long and $0.5 \mathrm{~m}$ in diameter or greater into the coal seams in highwalls, depending on the application methods. This system is more maneuverable than the CHM system and can be applied when shorter lengths of highwall are presented. It is also suited to recovering open cut end walls and major pillars of coal remaining after the CHM operation (Matsui et al. 2008).

One of the first true "highwall mining systems" to be demonstrated, the Metec miner system, was introduced in 1981 and featured in a number of trade exhibitions during the 1980s. As a successor of the Metec miner, the Bucyrus (formerly superior) highwall mining and American highwall systems are now attracting significant attention in the US. This system consists of a continuous miner, double auger flights, a stacker conveyor and a front-end loader basically as shown in Fig. 5. This system can excavate rectangular holes of over $300 \mathrm{~m}$ long, has maneuverability along the bench which is important for the higher

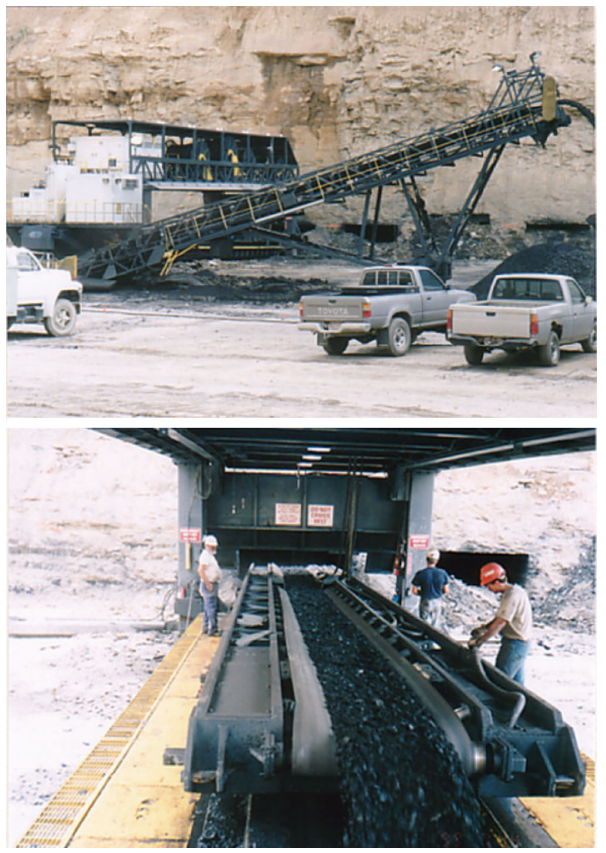

Fig. 2 Addcar system 


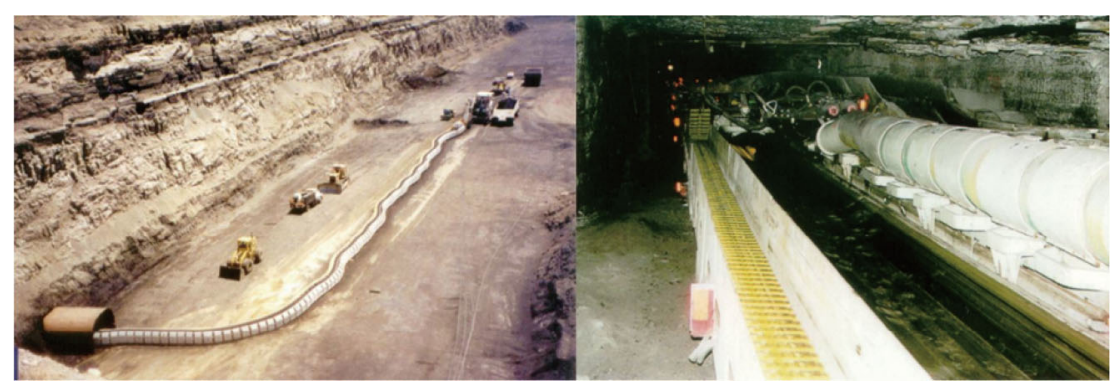

Fig. 3 Archveyor system

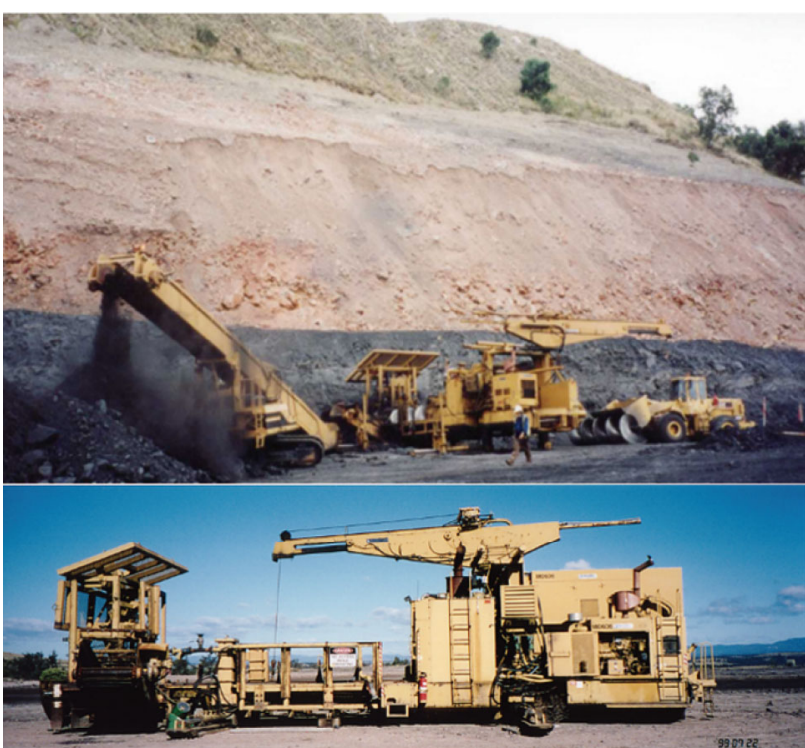

Fig. 4 Auger system

productivity, and the machine is equipped with four crawlers allowing for rapid positioning from hole to hole.

Highwall mining systems have improved mining operations due to their safety and productivity. However, the application is restricted by coal seam conditions such as the dip, thickness, roll, split of the seam, the existence of faulting and folding, etc. It is difficult or almost impossible to apply the system into steeper dipping coal seams, over $15^{\circ}$. Therefore, another type of system was developed, aimed at coal seams in the $16^{\circ}-25^{\circ}$ dip range. A highpowered auger machine, for use in seam dips of up to $23^{\circ}$, was developed and introduced at a coal mine in Australia (Matsui et al. 2003).

Highwall mining systems have been used extensively in the US and Australia due to their safe and economical mining method (Robertson et al. 1988; Michell 1999). However, in Indonesia, only a few highwall mining operations has been done (Furukawa et al. 2009).

\section{Application of highwall mining system in Indonesia}

Considering Indonesian coal seam conditions, only a few highwall mining operations had been conducted as shown in Fig. 6. According to their experience, dipping and rolling coal seam conditions always controlled its performance. Practical experience shows that a face of a $6 \mathrm{~m}$ thick seam would be mined by two augering lifts using $1.9 \mathrm{~m}$ diameter auger according to the original mining plan. However, the actual mining was quite different from the plan due to the coal seam conditions. As there were many dips, rolls and thickness changes in the seam, a single lift augering had to be used in the center of the seam. Therefore, the coal recovery was much less than had been planned.

Indonesian coal measure rocks are generally very weak (Anwar et al. 1999). In Indonesian archipelago, coal deposits are mainly distributed in the Islands of Sumatra and Kalimantan. The sedimentary basins within which the coals were deposited are very young geologically. Based on the time of deposition, coal measures are divided on the basis of their age into Paleogene and Neogene coal measures. In general, the majority of the coal is Eocene and Miocene in age. Sedimentary rock becomes stronger with age and tectonic stress. Uniaxial Compressive Strength also increases with age in most sedimentary rocks due to increased lithification and reduced porosity (Waltham 1994). Therefore, due to its very young geological age, Indonesia coal measure is a weak geological condition.

Some coal measures rocks such as shale, mudstone, and siltstone show an excessive slaking behavior leading to a severe deterioration of their mechanical properties. The weak immediate roof tends to fall easily and the continuous miner also tends to sink into the softened floor or slip on the floor. Moreover, the shape of openings may affect the stability of openings/pillar remarkably in such as weak geological conditions. Therefore, in order to discuss a suitable highwall mining design in Indonesia, a series of 


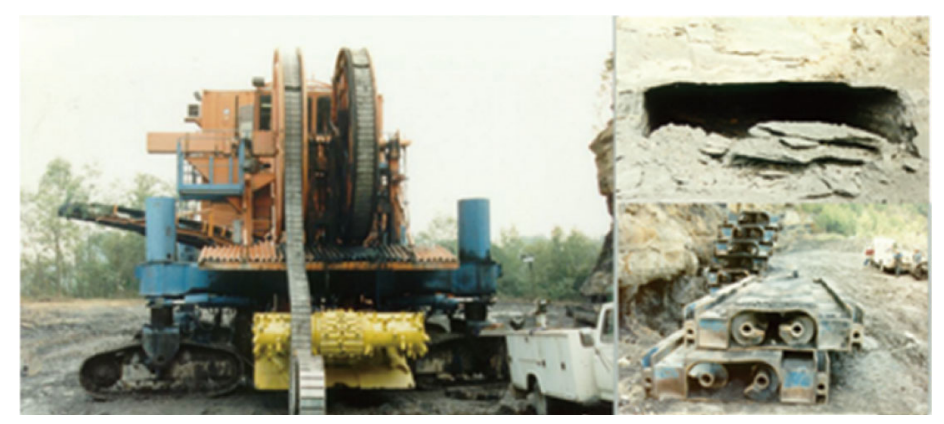

Fig. 5 Metec miner system

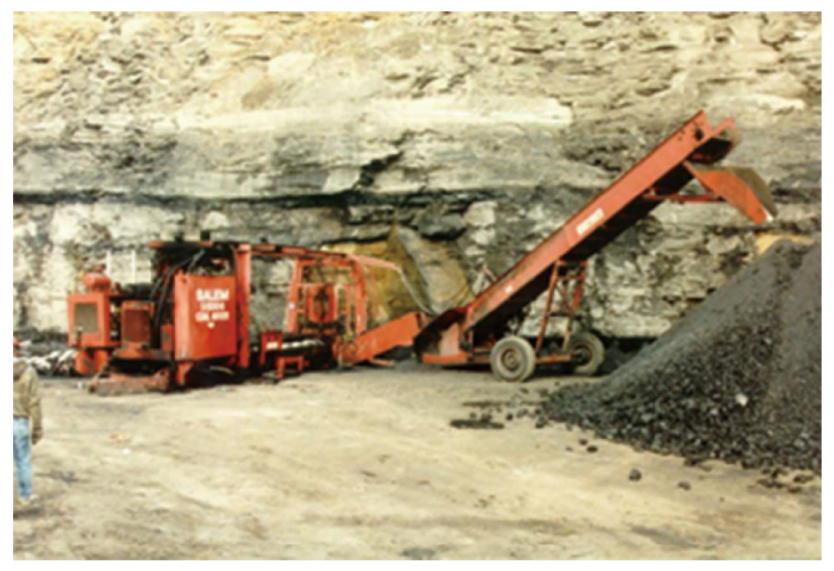

Fig. 6 Auger mining system in Indonesia

laboratory tests and numerical analysis were conducted in this research.

\section{Stability of openings/pillars in auger versus CMH mining systems}

\subsection{Laboratory test}

The formula for evaluating pillar strength for CHM (rectangular shape openings) has already been developed (Mark et al. 1995). However, the ones for the auger mining system have not been done yet. Therefore, in order to evaluate pillar strength of the auger mining system (circular shape openings) and discuss the difference between the stability of openings/pillar in auger mining system and that in $\mathrm{CMH}$ mining system, the laboratory tests using a test model were conducted.

Figure 7 shows the specimen used in this research. The specimen dimension was set such that it can simulate various pillar width to opening width ratio. The dimension of this specimen was $200 \mathrm{~mm}$ in thickness, $200 \mathrm{~mm}$ long and $150 \mathrm{~mm}$ high. The specimen consists of gypsum,

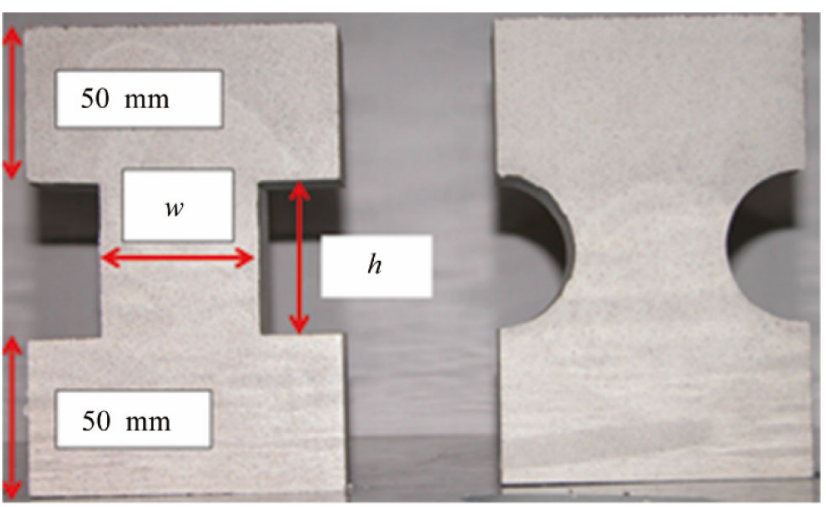

Fig. 7 Specimens for laboratory tests (left, square openings; right, circular openings)

cement and water (weight ratio, gypsum: cement: water = 1:1:1). The shapes of openings were a circle with a diameter of $50 \mathrm{~mm}$ or a square $50 \mathrm{~mm}$ on a side. The pillar width was varied in accordance to opening width. Four different pillar widths $(w), 25,50,75$ and $100 \mathrm{~mm}$, were evaluated. These specimens were stored under dry conditions for 3 days and then a loading test was conducted.

Figure 8 shows the relationship between the pillar strength index and ratio of pillar width/opening width of circular and square openings. Here, the pillar strength was defined as the following equation in order to eliminate the variation of material strength,

Pillar strength index

$$
=\frac{\text { Failure load }}{\text { Cross section of pillar } \times \text { UCS of material }}
$$

It can be seen from Fig. 8 that the pillar strength index increases with the increasing pillar width for both shapes of openings. The pillar strength for circular shape openings is about 1.2-1.3 times stronger than that of the rectangular shape. In order to evaluate the shape effect quantitatively, more detailed study has to be conducted under different geological conditions, in-situ stress conditions, etc. 


\subsection{Numerical analysis}

In order to discuss the stability of pillars and mine openings related to the shape of openings/pillars or the different mining systems, finite element modeling was also applied in this research. Non-linear analysis was also performed using the two-dimensional finite element method (FEM) cord 'Phase' ${ }^{2}$ (Rocscience Incorporation 2007). For simplicity, a two dimensional model was used in this analysis as shown in Fig. 9. The coal seam thickness is $3 \mathrm{~m}$. The immediate roof and floor are siltstone being $4 \mathrm{~m}$ thick and $3 \mathrm{~m}$ thick, respectively. The initial vertical stress $\left(\sigma_{\mathrm{v}}\right)$ was assumed to be the depth pressure $\left(\sigma_{\mathrm{v}}=\gamma h, \gamma\right.$ is the unit weight of overburden and $h$ is the cover depth or highwall height) and the initial horizontal stress $\left(\sigma_{\mathrm{h}}\right)$ was variable. Roller boundary was set at the outer side of the model as a boundary condition. Five circular openings with a diameter of $3 \mathrm{~m}$ or square openings $3 \mathrm{~m}$ on a side were excavated one after the other in the coal seam. The pillar width (w) between the two openings was assumed to be 3 and $1.5 \mathrm{~m}$ wide. The following well-known Hoek and Brown criterion was employed as a failure criterion:

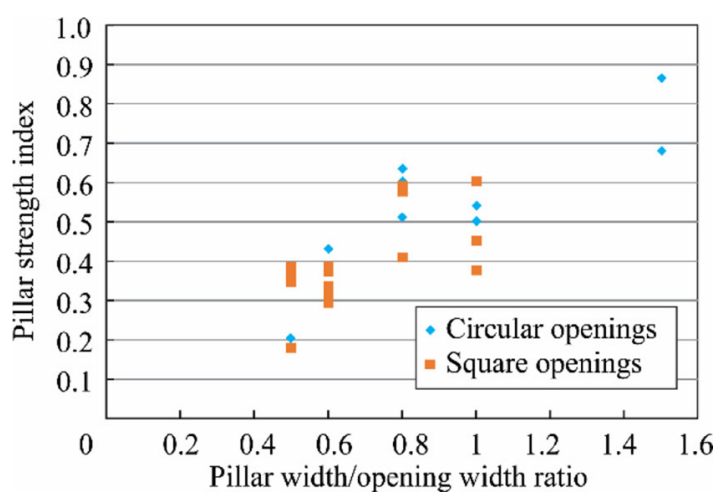

Fig. 8 Relationship between pillar strength and pillar width
$\frac{\sigma_{1}}{\sigma_{\mathrm{C}}}=\frac{\sigma_{3}}{\sigma_{\mathrm{C}}}+\left(m \frac{\sigma_{3}}{\sigma_{\mathrm{C}}}+s\right)^{\frac{1}{2}}$

where, $\sigma_{1}$ is the major principal stress at peak strength, $\sigma_{3}$ is the minor principal stress, $m$ and $s$ are constants that depend on the properties of the rock and the extent to which it had been broken before being subjected to the failure stresses, and $\sigma_{\mathrm{C}}=$ uniaxial compressive strength of the intact rock material. The mechanical properties and parameters of the coal and rocks are listed in Table 1.

Figures 10,11 and 12 show the results of the numerical analysis. From these figures, it can be seen clearly that the stability of openings/pillars in the auger mining system is higher than that in CHM. Figure 10 shows the failure development around the openings at different depths. With increasing the depth, the failure zones develop around the openings and in the pillars. Figure 11 also shows the failure development around the openings under the different initial stresses. The failure conditions depend on the stress conditions. Under high horizontal stress conditions $\left(\sigma_{\mathrm{h}} /\right.$ $\sigma_{\mathrm{z}}=1.5$ ), the roof and floor of the openings tend to induce shear failure easily. Figure 12 shows the failure development around the openings with narrow pillars. Compared with Fig. 10, the narrow pillar in Fig. 12 shows less stability and the pillars fail much more severely in square openings. This situation will lead to unstable work conditions, and sometimes the cutting machine is caught in the opening being impossible to withdraw. On the other hand, in circular openings, no obvious and/or large pillar failure can be recognized even until a depth of $100 \mathrm{~m}$.

It can be concluded that the stability of pillars and mine openings in auger mining systems is much higher than that in CHM and an auger mining system is suitable for such as very weak/poor strata conditions. However, this mining system has to be improved to cope with steeper coal seams and water problems in the face in order to increase the extraction ratio and maintain the highwall stability.

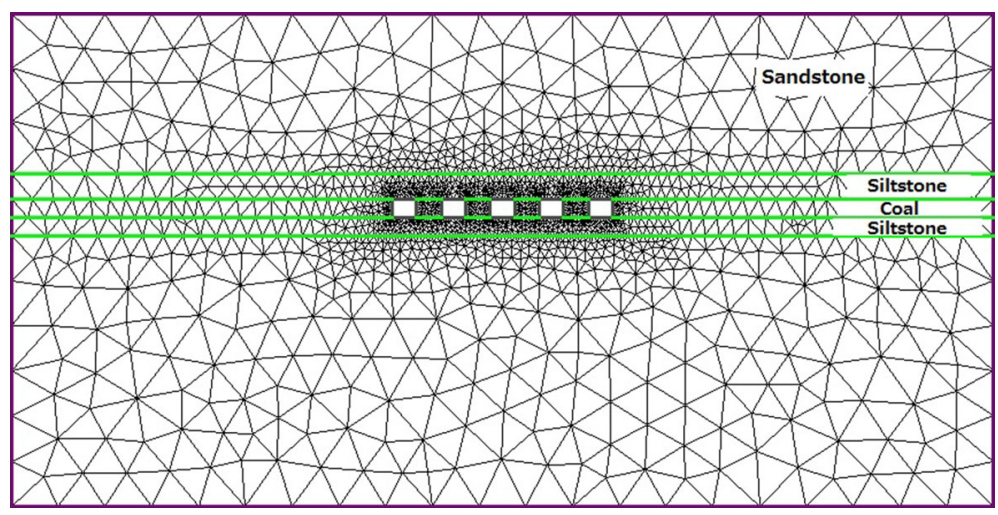

Fig. 9 Two-dimensional finite element model 
Table 1 Mechanical properties of rocks used in numerical analysis

\begin{tabular}{lllllll}
\hline Rocks & $\begin{array}{l}\text { Young's modulus } \\
(\mathrm{MPa})\end{array}$ & Poisson's ratio & $\begin{array}{l}\text { Uniaxial compressive } \\
\text { strength } \\
(\mathrm{MPa})\end{array}$ & $m$ & $s$ & $\begin{array}{l}\text { Unit weight } \\
\left(\mathrm{MN} / \mathrm{m}^{3}\right)\end{array}$ \\
\hline Sandstone & 5700 & 0.28 & 26.6 & 7.50 & 0.10 & 0.0243 \\
Siltstone & 4650 & 0.27 & 20.9 & 2.00 & 0.02 & 0.0247 \\
Coal & 1530 & 0.30 & 11.9 & 2.08 & 0.07 \\
\hline
\end{tabular}

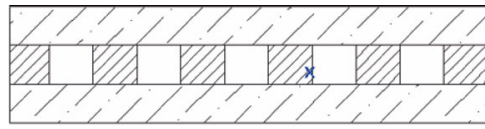

$40 \mathrm{~m}$

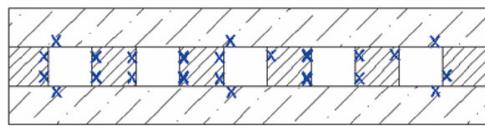

$60 \mathrm{~m}$

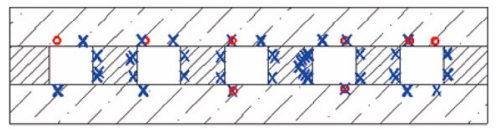

$80 \mathrm{~m}$
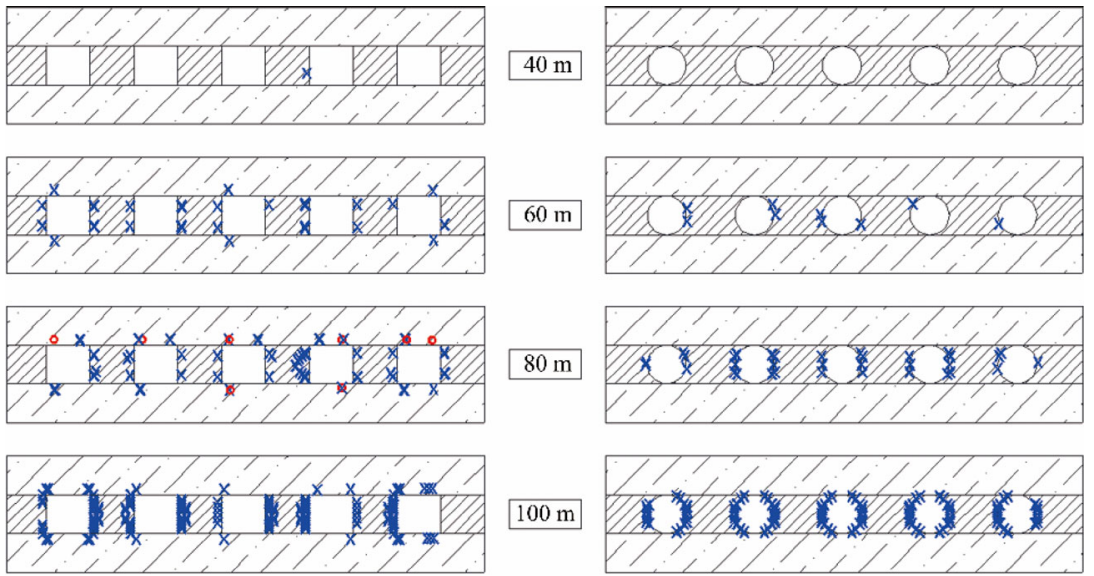

O Tensile failure
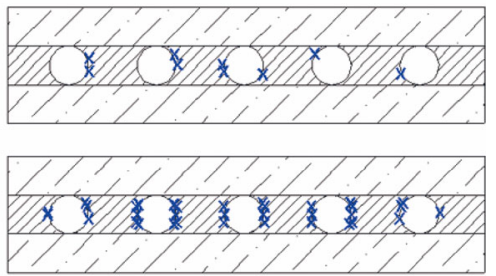

$100 \mathrm{~m}$

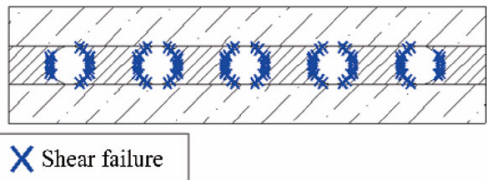

Fig. 10 Failure development around the openings at different depths (left, square opening; right, circular opening; $\sigma_{\mathrm{h}} / \sigma_{\mathrm{z}}=0.75$; width of opening: width of pillar $=1: 1$ )
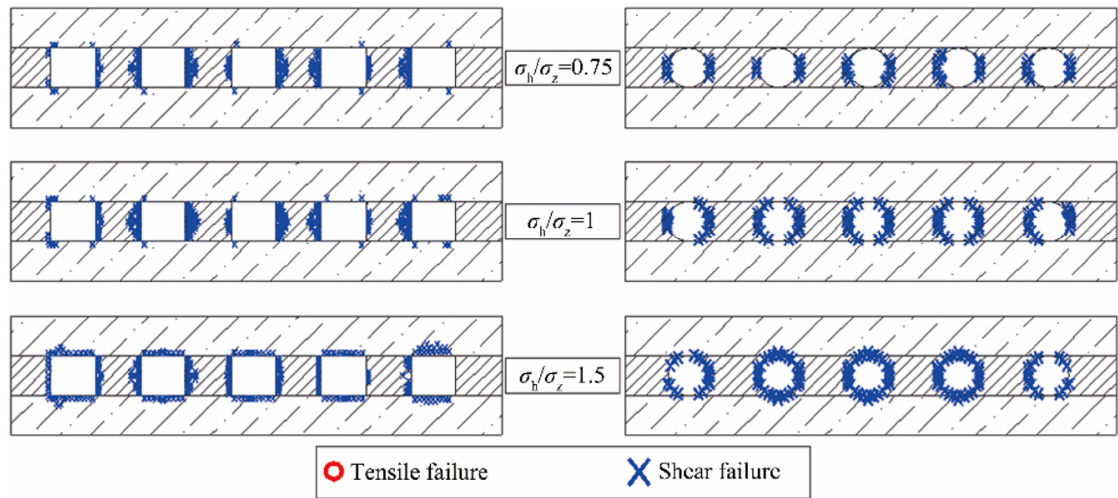

Fig. 11 Failure development around the openings under the different initial stress (left, square opening; right, circular opening; depth = $100 \mathrm{~m}$; width of opening: width of pillar $=1: 1$ )

\section{Application of backfilling system}

In order to improve the stability of openings and pillars and to increase the coal recovery, the application of backfilling system was also discussed by means of numerical analysis and laboratory tests.

\subsection{Backfilling systems}

Waste disposal in underground mines is not a revolutionary concept. Waste rocks have been used in the world for many years as backfilling materials to provide additional support to underground excavations in mines. Recently, for the lack 


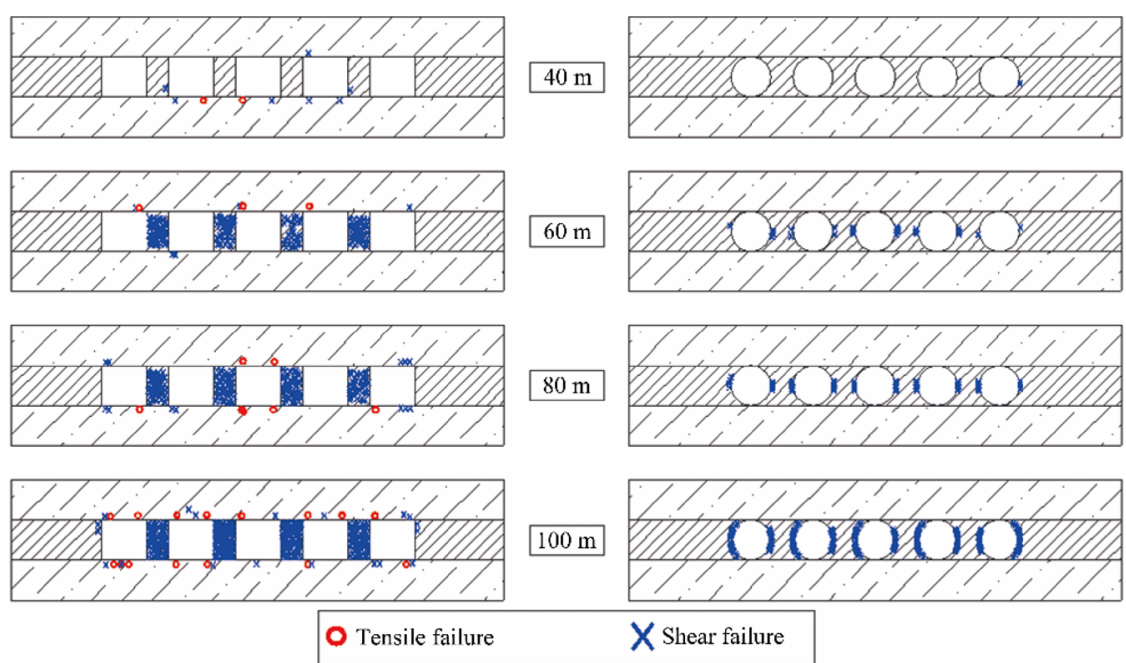

Fig. 12 Failure development around the openings with narrow pillars (left, square opening; right, circular opening; $\sigma_{\mathrm{h}} / \sigma_{\mathrm{z}}=0.75 ;$ width of opening: width of pillar $=2: 1$ )

of a dumping site the use of backfill for regional and local support has been receiving increasing attention in the mining industry.

According to the previous research work (Afrouz 1994), backfilling presents the following merits to the underground coal mines:

(1) Fills the excavated areas, promoting better support and ground control.

(2) Provides a better environmental control on the waste rocks and coal preparation plant wastes.

(3) Increases coal recovery, especially in room and pillar mining and highwall mining systems.

(4) Reduces ventilation short-circuiting between adjacent mining sites.

(5) Reduces cost of waste transportation to the mine surface dumping sites and tailing ponds, and associated up-keeping and monitoring of these facilities.

In the USA, increased opposition from environmental groups is severely restricting the operation and planning of large-scale surface mines. Some projects of mountaintop removal mining have to be cancelled and downsized. In this case, as discussed in the previous section, the highwall mining system would be applicable and useful for the protection of the environment and reclamation. The backfilling would increase the coal extraction ratio, keep the pillars and the highwall stable and control the subsidence at the surface.

The required strength of the backfill depends on the strata and mining conditions: cover depth, rock types and properties, mining method, etc. At a shallow mine, the required strength is not critical compared to that at a deep mine. According to the research work in South Africa, backfilling shallow underground room and pillar mines with pulverized fly ash slurry could significantly improve the mine operating conditions by providing improved roof support and increased extraction ratio (Wagner and Galvin 1979). The research also suggests that the complete filling of the rooms, up to the roof level, is not necessary for improved roof control. Filling up to $70 \%$ of the pillar height provided adequate confinement that constrained the lateral expansion of the pillar under concentrated compressive stresses. Moreover, by providing confinement to the pillars, thick coal seams have been successfully mined with a subsequent reduction of pillar height to width ratio and improved load bearing capacity of the pillars.

Backfilling materials that are of concern to the mining industry can be broadly classified into the following three categories:

(1) Waste originating from coal mines.

(2) Waste originating from coal burning power plants.

(3) Waste originating from other industries.

\subsection{Finite element analysis about backfilling effects}

Finite element modeling was used to clarify the effectiveness of the backfilling system on the stability of pillar, openings and highwall. For simplicity, the two dimensional model was used as shown in Fig. 9. The height of the highwall $(h)$ was assumed to be $60-100 \mathrm{~m}$. Five rectangular openings being of $4 \mathrm{~m}$ wide and $3 \mathrm{~m}$ high were excavated one after the other in the coal seam. After the excavation of each opening, the opening was backfilled. And then the next opening was excavated. The pillar width (w) between two openings was assumed to be 4 and $2 \mathrm{~m}$ wide. The mechanical properties and parameters of two different backfilling materials were simulated and listed in Table 2. 
Table 2 Mechanical properties of backfilling materials used in numerical analysis

\begin{tabular}{llllrrr}
\hline Materials & $\begin{array}{l}\text { Young's modulus } \\
(\mathrm{MPa})\end{array}$ & Poisson's ratio & $\begin{array}{l}\text { Uniaxial compressive } \\
\text { strength } \\
(\mathrm{MPa})\end{array}$ & $\begin{array}{c}\mathrm{s} \\
\left(\mathrm{MN} / \mathrm{m}^{3}\right)\end{array}$ \\
\hline Backfill 1 & 2000 & 0.3 & 20 & 10.0 & 0.1 & 0.020 \\
Backfill 2 & 500 & 0.3 & 10 & 7.5 & 0.1 & 0.017 \\
\hline
\end{tabular}

(a) Pillar width $w=4 \mathrm{~m}$
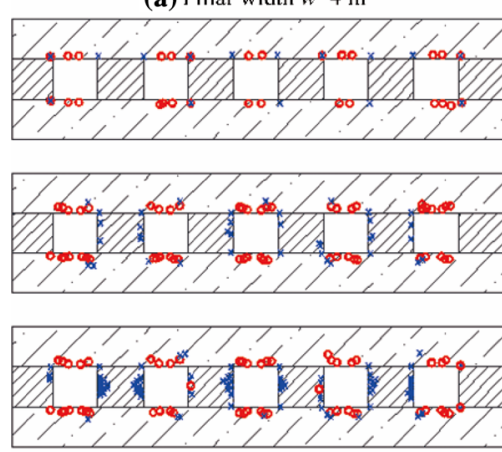

- Tensile failure (b) Pillar width $w=2 \mathrm{~m}$

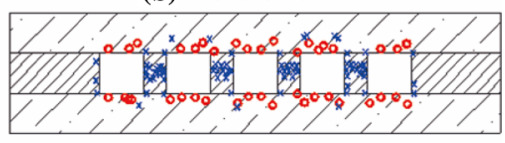

$80 \mathrm{~m}$

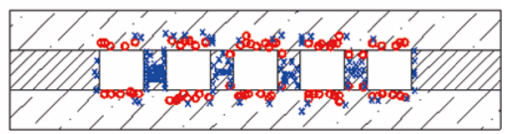

$100 \mathrm{~m}$

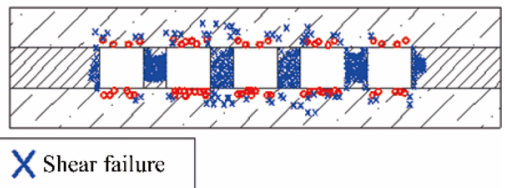

Fig. 13 Failure development around the openings with wide and narrow pillar $\left(\sigma_{\mathrm{h}} / \sigma_{\mathrm{z}}=0.75\right)$

Figure 13 shows the failure development around the openings with wide and narrow pillars. With the narrow pillar, the openings show the less stability and the pillars fail much severer than the wide pillar case. This situation will lead to unstable work conditions, and sometimes the cutting machine would be caught in the opening being impossible to withdraw.

Figure 14 shows the failure development around the openings with backfilling. It is clear that the backfilling helps the openings keep stable compared to the nonbackfilled cases as shown in Fig. 13. However, at greater depths, the effectiveness of backfilling cannot be obtained well. In such a case, we have to consider the use of wider pillar, narrow opening and stronger backfilling material.

Although it is clear from the numerical model that the backfilling improves the pillar stability shown by the reduction of plastic zone, the mechanism and reason is not well understood. Therefore, laboratory test must be carried out to unveil the role of backfilling in strengthening the pillar.

\subsection{Laboratory tests about backfilling effects}

Result in Fig. 14 suggests that the backfilling improve the pillar stability. This could be caused by confinement effect of backfilling and the infiltration of backfilling slurry content into the failure zone improves mechanical properties of the broken pillars. In order to examine the behavior of backfilled pillars, modeled pillar was set up and tested in the laboratory. Cylindrical cores were drilled out and prepared to simulate pillar models from Ainoura sandstone block sample.

\subsubsection{Test procedures}

The size of the prepared pillar models is around $25 \mathrm{~mm}$ in diameter and $60 \mathrm{~mm}$ in length. These samples were cured for 4 weeks under the constant environmental conditions: $100 \%$ relative humidity and $25{ }^{\circ} \mathrm{C}$.

After the above cure, the pillar models that were not backfilled were set in the stiff testing machine and tested under compressive loading to obtain the complete stressstrain curves. This test is the same as the standard compression test.

In order to investigate the backfilling effects, two tests were performed. One is for backfilled pillar models and the other is for the backfilled fractured pillar models. The backfilled model was made from the pillar model that was set in the polyvinyl chloride (PVC) tube and filled with the backfill mixture as shown in Fig. 15. Three backfill heights such as 25,40 and $50 \mathrm{~mm}$ were considered in the tests. Five backfill mixtures consisting of Portland cement, fly ash and water were considered as listed in Table 3. These backfilled pillar models were cured under the same conditions as pillar models mentioned before. 


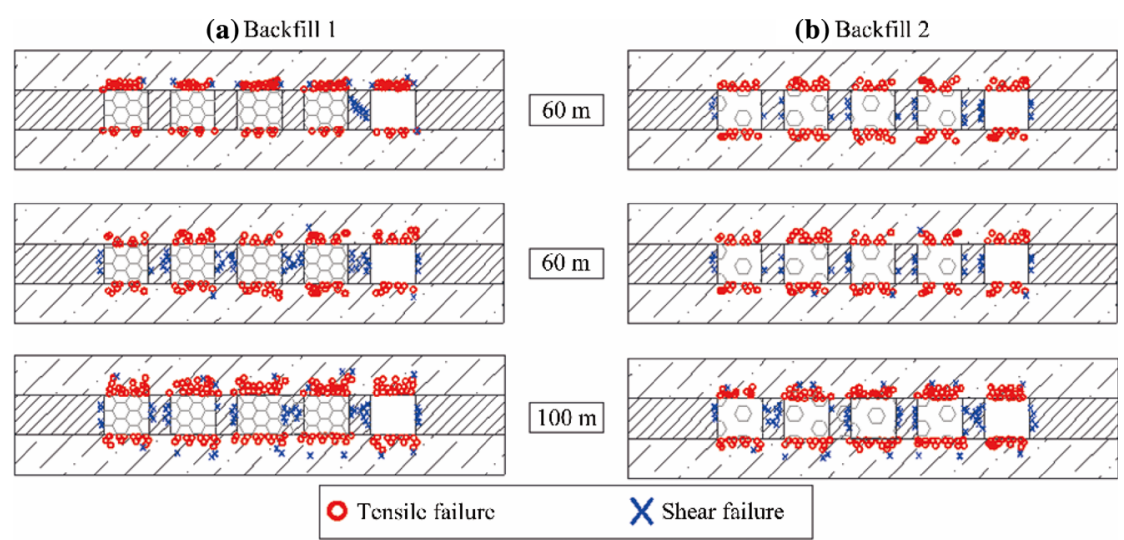

Fig. 14 Failure development around the openings with backfilling $\left(\sigma_{\mathrm{h}} / \sigma_{\mathrm{z}}=0.75\right.$, pillar width $\left.w=2 \mathrm{~m}\right)$

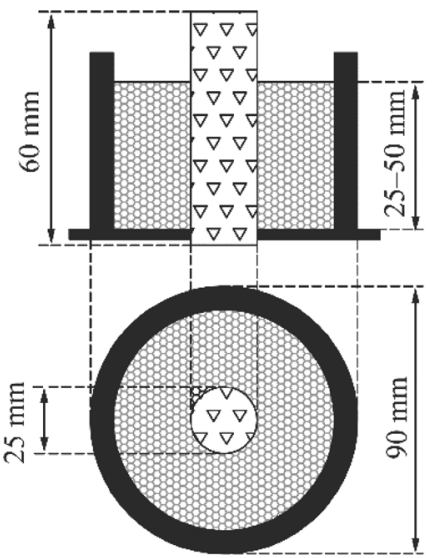

四
Sandstone
眳 Backfill mixture
PVC tube

Fig. 15 Backfill model for standard compression test

Table 3 Contents of each backfill mixture (weight ratio)

\begin{tabular}{llll}
\hline No. & $\begin{array}{l}\text { Portland } \\
\text { cement }(\mathrm{C})\end{array}$ & $\begin{array}{l}\text { Fly } \\
\text { ash }(\mathrm{F})\end{array}$ & $\begin{array}{l}\text { Water } \\
(\mathrm{W})\end{array}$ \\
\hline 1 & 10 & 0 & 5 \\
2 & 8 & 2 & 5 \\
3 & 5 & 5 & 5 \\
4 & 3 & 7 & 5 \\
5 & 1 & 9 & 5 \\
\hline
\end{tabular}

The backfilled fractured pillar models were obtained from the above usual compression tests where the complete stress-strain curves were obtained. After the compression test, the fractured pillar was set in the PVC tube, and then filled up to the described height with the backfill mixture and cured as mentioned before. Three to five models were tested for each test condition.

\subsubsection{Test results and discussion}

Figure 16 shows the mechanical properties of backfill mixtures. Curing time shows definite effect on the

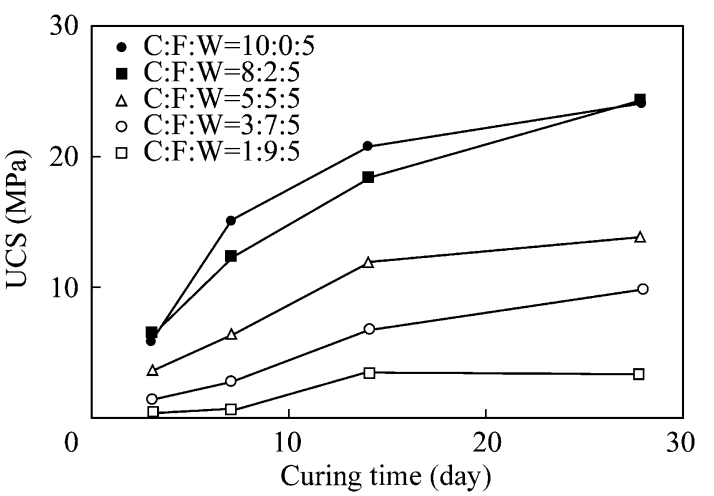

(a) UCS

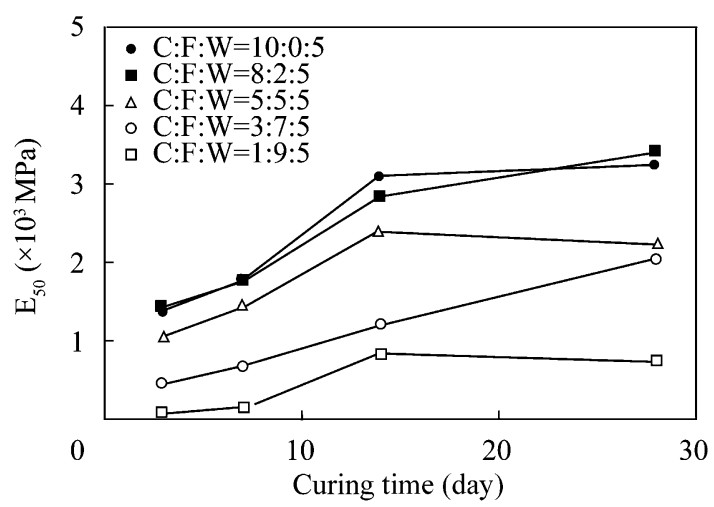

(b) Young's modulus

Fig. 16 Mechanical properties of backfill mixtures under different curing time

mechanical properties such as uniaxial compressive strength (UCS) and tangent Young's modulus at $50 \%$ of peak stress $\left(\mathrm{E}_{50}\right)$ in 2 weeks. Increasing the fly ash content decreases the mechanical properties.

Figure 17 shows the complete stress-strain curves of backfilled pillar models under the different backfilling heights. Backfilling improves the behavior of the pillar, increasing the Young's modulus, the peak stress and the residual stress. 


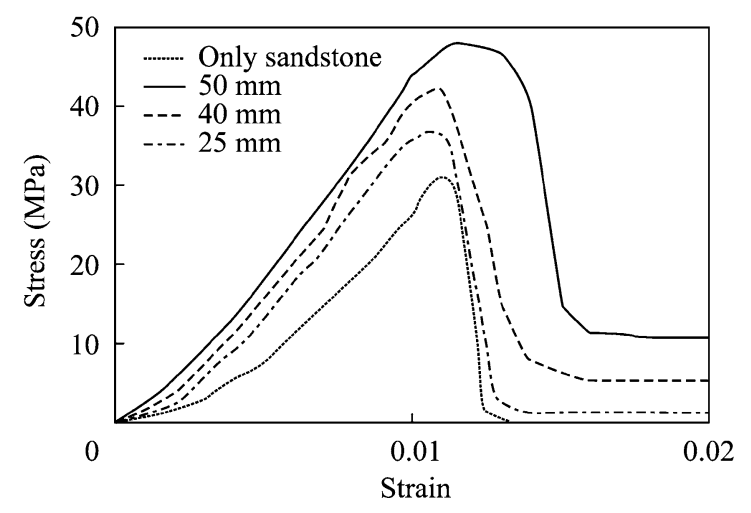

Fig. 17 Stress-strain curve of backfilled pillar models under different backfilling heights

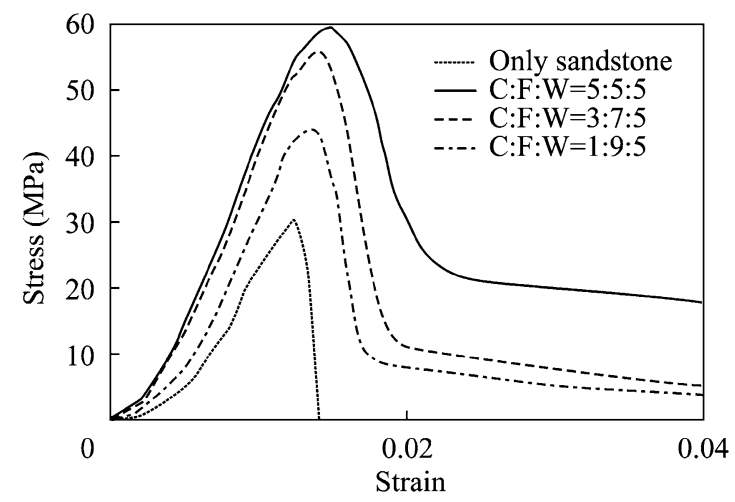

Fig. 18 Stress-strain curve of backfilled pillar models under different backfill mixtures contents

Figure 18 shows the complete stress-strain curves of backfilled pillar models under the different mixture contents. Increasing Portland cement also improves the properties due to the high confinement of backfilling.

From these test results using the backfilled pillar models, the effectiveness of backfilling on the pillar behavior is shown especially in the peak stress and behavior in the post-peak region.

Figures 19 and 20 show the complete stress-strain curves of pillar models and backfilled fractured pillar models under the different backfilled heights and the different mixture contents, respectively. Although the pillar models show peak stress clearly, they show any residual stress after peak stress. It is difficult to mobilize the function as a pillar under poor strata and high stress conditions. However, backfilling plays an important role in increasing the peak stress and residual stress, though not increasing the Young's modulus.

From these test results using the backfilled fractured pillar models, fractured pillars restore their strength by backfilling. It means that backfilling improves the fractured pillar behavior very well.

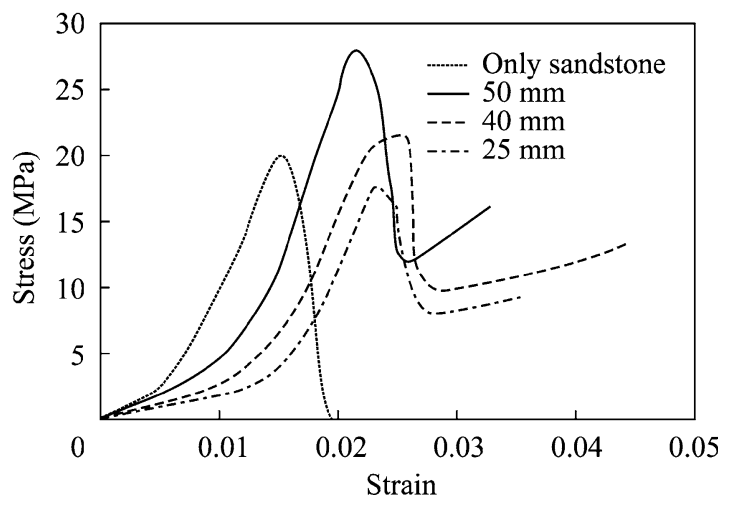

Fig. 19 Stress-strain curve of backfilled fractured pillar models under different backfilling heights

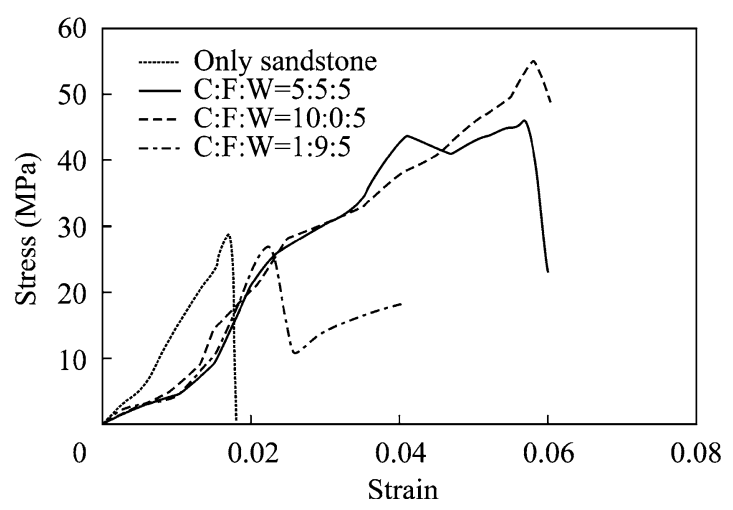

Fig. 20 Stress-strain curve of backfilled fractured pillar models under different backfill mixtures contents

\section{Conclusions}

Highwall mining systems can sometimes be the final mining method used in open cut mines, or it can serve as a means of transition, with low capital cost, from surface mining to underground mining. From the results of a series of laboratory tests and numerical analyses, stability of openings/pillars in the auger mining system is higher than that in CHM. The pillar strength for circular shape openings in the auger mining system is about 1.2-1.3 times stronger than that of the rectangular shape openings in CHM. The pillar strength index increases with the increasing pillar width for both shapes of openings. It is also found that backfilling improve the pillar stability. It improves the pillar stability by, increasing its Young's modulus, the peak stress and the residual stress. From test results using the backfilled fractured pillar models, fractured pillars restore their strength by backfilling. It means that backfilling improves the fractured pillar behaviour very well. However, at greater depths, the effectiveness of backfilling cannot be obtained well. Based on this result, the highwall mining operation can be applied even in weak 
geological conditions by application of the appropriate mining system and/or backfilling system.

Open Access This article is distributed under the terms of the Creative Commons Attribution 4.0 International License (http://crea tivecommons.org/licenses/by/4.0/), which permits unrestricted use, distribution, and reproduction in any medium, provided you give appropriate credit to the original author(s) and the source, provide a link to the Creative Commons license, and indicate if changes were made.

\section{References}

Afrouz AA (1994) Placement of backfill. Min Eng 153:205-211

Anwar HZ, Shimada H, Ichinose M, Matsui K (1999) Slaking durability of the improvement of coal mine shales behavior. Proceeding of the international symposium on mining science and technology, Beijing, pp 343-346

Furukawa H, Matsui K, Sasaoka T, Shimada H (2009) Application of a punch mining system to Indonesian coal mines. Proceedings of the 2nd international symposium of novel carbon resources science, earth resource science and technology, Bandung: III1-9

Mark C, Chase FE, Campoli AA (1995) Analysis of retreat mining pillar stability. Proceedings of 14th conference on ground control in mining, pp 49-59

Matsui K, Yabuki A, Shimada H, Sasaoka T, Ueda T, Yuasa T (2003) A practical trial to increase the coal recovery in highwall auger mining in Australia. Proceedings of 12th international symposium on mine planning and equipment selection, pp 205-208

Matsui K, Sasaoka T, Shimada H, Ueda T, Kramadibrata S, Sulistianto B (2008) Highwall mining systems at surface coal mines in Indonesia. Coal Int 256(3):28-31

Michell G (1999) Benefits of longwall punch mining. Proceedings of the 2nd annual longwall mining summit, p 8

Robertson BN, O'Regan G, McKew M (1988) Longwall punch mining from open cut highwalls. Proceedings of the 21 st century higher production coal mining systems-their implications, pp 215-220

Rocscience Incorporation. (2007) Application of the finite element method to slope stability. http://www.rocscience.com/library/ pdf/SlopeStabilityUsingPhase2.pdf. Accessed 17 Feb 2007

Seib WT (1993) Strip mining. In: Hargraves AJ, Martin CH (eds) Australasian coal mining practice, 2nd edn. Australasian Institute of Mining Metallurgy, Carlton, pp 238-242

The Virginia Center for Coal and Energy Research (VCCER) (2008) Meeting projected coal production demands in the USA, chapter 3: mining technology and resource optimization. Blacksburg: The Virginia Center for Coal and Energy Research

Wagner H, Galvin JM (1979) Use of hydraulically placed PFA to improve stability in bord and pillar workings in South African collieries. Proceedings of symposium on the utilization of pulverized fuel ash, p 27

Waltham AC (1994) Foundations of engineering geology. The Alden Press, Oxford 